\title{
Prevalence of Rheumatoid Arthritis in the Southern Part of Denmark
}

\author{
Jens K. Pedersen ${ }^{*}$, Anders J. Svendsen, Kim Hørslev-Petersen
}

Research Unit, King Christian X Hospital for Rheumatic Diseases, Toldbodgade 3, 6300 Graasten, Denmark

\begin{abstract}
The aim of the present study was to estimate the prevalence of rheumatoid arthritis in the southern part of Denmark. Using a screening questionnaire, telephone interview, register data, and a clinical examination cases were ascertained from a random sample of 4995 individuals over the age of 15 . As case definition we used the original and modified 1987 American College of Rheumatology classification criteria. The overall point prevalence was $0.26 \%$ (95\% confidence interval: $0.13-0.39)$ in the total sample and $0.35 \%$ (95\% confidence interval: $0.17-0.52)$ among the responders; the cumulative prevalence was $0.75 \%$ (95\% confidence interval: $0.52-0.97)$ in the total sample and $0.92 \%(95 \%$ confidence interval: 0.62-1.21) among the responders.

The cumulative prevalence was higher than in other studies combining the results of a survey with register data. The point prevalence was underestimated due to low participation rate in the clinical examination and remission among the participants.
\end{abstract}

Keywords: Rheumatoid arthritis, prevalence, survey, registers.

\section{INTRODUCTION}

In most populations of European origin, the overall prevalence of rheumatoid arthritis (RA) is $0.5 \%$ to $1 \%$ [1]. Only a few studies have investigated whether the prevalence of RA has changed over time but some reports from populations of different origin have indicated that the prevalence may be decreasing [2-6].

In Denmark, the point prevalence of RA has previously been estimated in two studies. In a nationwide sample from the $1960 \mathrm{~s}$, the overall point prevalence of probable, definite and classic RA according to the Rome criteria was $0.85 \%$ [7]. In a study from the Faroe Islands in the North Atlantic Ocean in the 1980s, in the age group between 40 and 74 years the point prevalence according to the 1987 American College of Rheumatology (ACR) criteria was 1.1\% [8]. There is some evidence that a high dietary intake of oil-rich fish protects against the development of RA [9] and a small study from an isolated, fish-eating community, like the Faroe Islands, may not give relevant nor precise estimates of RA in the total Danish population. Moreover, data on the prevalence of RA may be used for the planning of healthcare provision and current estimates are therefore essential.

In the present study we report the point prevalence and the cumulative prevalence of RA [10] in a random sample of the population in the southern part of Denmark in 2004. For the ascertainment of cases we used a screening mail questionnaire, telephone interview, register data, and a clinical examination.

*Address correspondence to this author at the Research Unit, King Christian X Hospital for Rheumatic Diseases, Toldbodgade 3, 6300 Graasten, Denmark; Tel: +45-73654000; Fax: +45-73652002;

E-mail: jensk@dadlnet.dk

\section{MATERIALS AND METHODOLOGY}

\section{Setting and Sample Size}

Using a unique identification number (CPR-number) given to all Danish citizens by an office under the Department of the Interior, a random sample of 5000 individuals over the age of 15 was drawn from the County of South Jutland (Fig. 1). With a $60 \%$ response rate, $3 \%$ of the responders self-reporting RA and $20 \%$ in whom RA would be ascertained at a clinical examination, we expected an overall point prevalence of $0.6 \%$ (95\% confidence interval (CI): 0.4-1.0).

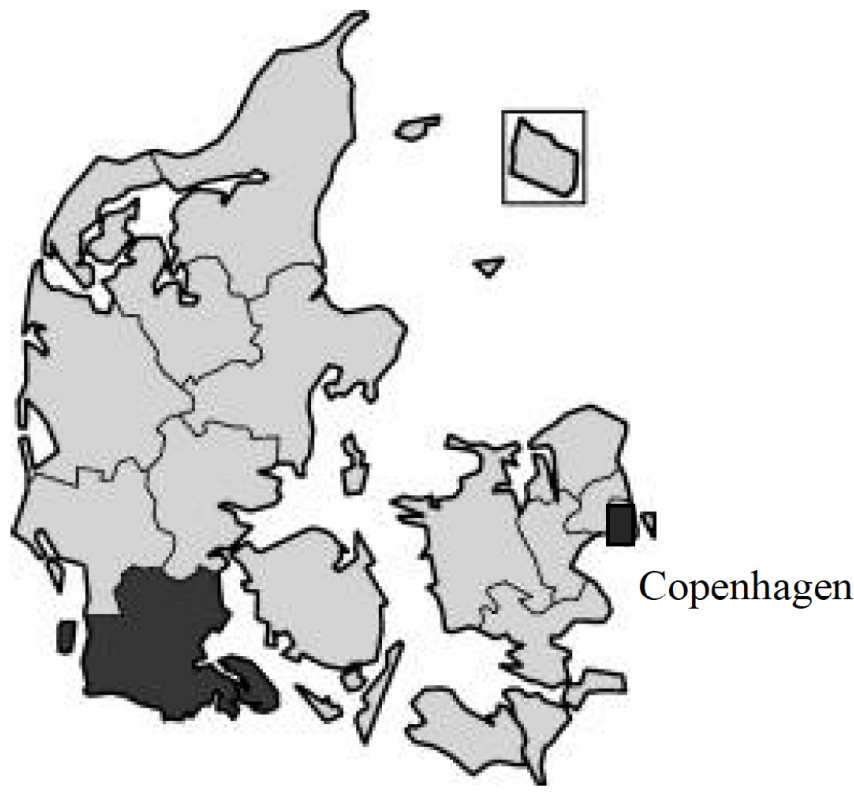

Fig. (1). The County of South Jutland, a region in the southern part of Denmark with a 2004 population of 203,799 individuals over the age of 15 . 


\section{Screening Mail Questionnaire}

The screening mail questionnaire consisted of five items: 1) "Have you or have you ever had RA"; 2) "Have you or have you ever had more than two swollen joints at the same time"; 3) "Have you or have you ever had joint stiffness lasting more than one hour in the morning"; 4) "Have you ever been diagnosed as having RA by a doctor"; 5) "Have you ever been examined or treated for RA by a doctor". Additionally, it was possible to write a short message on the questionnaire. We sent out one reminder including the questionnaire and a stamped, pre-addressed return envelope.

The items in the questionnaire were selected by the authors and evaluated for face validity by a group of rheumatologists and a linguist. In pilot test with patients from a rheumatology hospital self-administration of the questionnaire was observed by a research nurse and found to be feasible. In 67 individuals ( 29 patients with RA, 18 with other rheumatic diseases, 20 healthy individuals (employees)) recruited from the same setting the sensitivity and specificity of the first item on the questionnaire was 1.00 (95\% CI: $0.88-1.00)$ and $0.82 \quad(95 \%$ CI: $0.66-0.92)$, respectively. Answering "yes" to all five items the sensitivity was 0.79 (95\% CI: 0.60-0.92) and specificity 0.90 (95\% CI: 0.75- 0.97). Using Cohen's kappa [11] in a test-retest study in 53 individuals with a time interval of six weeks the agreement for the first item was 1.00 (95\% CI: 1.00-1.00) and for all five items it was 0.91 (95\% CI: 0.80-1.00).

\section{Register Data}

Using the CPR-numbers individuals from the sample were identified in nationwide and local registers. Medical records or questionnaire data were subsequently scrutinized to ascertain cases that cumulatively fulfilled the 1987 ACR classification criteria [12].

Danish National Hospital Register (DNHR): The DNHR is a nationwide register with administrative data on in- and outpatients from Danish hospitals and the register may be used for epidemiological research. In the DNHR the diagnoses at the discharge of a patient are registered according to the International Classification of Diseases (ICD) [13]. In the present study all individuals from the sample with positive RA diagnoses in the DNHR from 1978 to 2003 (ICD-8 codes 712.* and ICD-10 codes M05.0M05.9 and M06.0-M06.9) were identified and copies of medical records from relevant admissions were requested from the hospitals.

The King Christian X Hospital for Rheumatic Diseases: At the time of the study the rheumatology hospital served as a referral centre for patients with rheumatic diseases from the County of South Jutland. In Denmark hospitals are required to maintain medical records for ten years after the last contact with a patient, but at the rheumatology hospital historical medical records are, as a rule of thumb, not destroyed. At the rheumatology hospital we expected to be able to identify patients with RA using data from the DNHR. However, the DNHR does not include data before 1978, data on outpatients with RA from the rheumatology hospital that had not been discharged at the time of the present study, or patients that might have been misclassified at discharge. Therefore, the hospital register was searched by hand for medical records on individuals from the sample who answered "yes" to the first item on the screening mail questionnaire (i.e. self-reported RA), wrote a message on the questionnaire indicating that they could have RA, or had positive RA diagnoses in the DNHR.

The Public Health Insurance: In Denmark, the total population is covered by the Public Health Insurance. Private practising rheumatologists are reimbursed by the Health Insurance if their patients are treated with disease-modifying anti-rheumatic drugs (DMARDs). As far as we know, the accuracy of data from the Public Health Insurance has not been evaluated. We were given access to Health Insurance data from 1997 to 2004 to identify individuals from the sample treated with DMARDs by private practising rheumatologists. The rheumatologists would then be asked by questionnaire to document if the 1987 ACR list criteria had been fulfilled.

General practice: If informed consent was given at the clinical examination and the classification criteria for RA had not been fulfilled, general practitioners (GPs) were asked by questionnaire to document if the 1987 ACR list criteria had been fulfilled.

\section{Clinical Examination}

The responders to the mail questionnaire were invited to attend for a clinical examination at the rheumatology hospital in the following ways: A. Directly, if they: 1) answered "yes" to all five items on the questionnaire and did not make any comments that, judged by one of the investigators (JKP), contradicted that they could have RA; 2) did not answer "yes" to all items, but wrote a message on the questionnaire that, judged by one of the investigators (JKP), was conceived as being a strong indicator of RA; 3 ) were registered with RA diagnoses in the DNHR. B. After a telephone interview carried out in the responders who answered "yes" to the first item on the questionnaire and had not been invited directly.

In the telephone interview the individuals were asked when the first symptoms of RA appeared, to indicate which joint areas that were affected, if the involvement of joints was symmetrical, if they currently had joint swelling or deformities, if they had ever had a positive test for rheumatoid factors or radiographs taken that indicated RA, if they had ever been diagnosed with other rheumatic diseases than RA, and if drugs for RA had ever been prescribed by a doctor. The individuals who at the telephone interview were judged by the interviewer (JKP) to be potential RA cases were invited to the examination.

At the rheumatology hospital the individuals were examined by one of five rheumatologists who all were trained joint assessors. If two or three criteria of the modified 1987 ACR list format [14] were fulfilled, a test for IgM rheumatoid factors (Enzyme-Linked Immunosorbent Assay, cut-off: $8 \mathrm{IU} / \mathrm{ml}$ ) and radiographs of hands and feet were carried out. The modified 1987 ACR criteria include both malalignment and joint swellings as signs of RA. Accordingly, the modified 1987 ACR criteria identifies both individuals with signs of current and previously active RA and in a previous survey the modified criteria were more sensitive than the 1987 ACR criteria for ascertaining RA cases [14]. 


\section{Statistics and Ethics}

When calculating the cumulative prevalence, individuals who fulfilled the modified 1987 ACR criteria at the examination, or had previously fulfilled the 1987 ACR criteria documented in medical records or by questionnaire, were counted as ever $R A$ cases. When calculating the point prevalence, individuals who satisfied the modified 1987 ACR criteria at the examination were counted as cases. Using the direct method, the prevalence estimates were adjusted for age and sex to the 2004 Danish population and reported with $95 \%$ CI. Population data were provided by Statistics Denmark. Statistics were done using Stata, version 8.2.

The study was approved by the local ethics committee (reference no. 2426-02) and the Danish Data Protection Agency (reference no. 2002-41-2231).

\section{RESULTS}

\section{Response Rate and Register Data}

The screening questionnaire was send to 5000 individual but the addresses of five individuals were unknown and the effective sample size was 4995 (Fig. 2). Overall, 68\% returned the questionnaire and the response rate was highest among the elderly (Table 1). Among the non-responders the mean age was 45 years and $45 \%$ were females, among the responders the mean age was 52 years and $55 \%$ were females.

A total of 278 individuals self-reported RA by answering yes to the first item on the screening questionnaire, or had RA diagnoses in the DNHR, or made comments in the questionnaire indicating that they could have RA. Medical records or questionnaire data from hospitals and GPs were available in 110 individuals. According to the Public Health Insurance no individuals from the sample had been treated with DMARDs by private practising rheumatologists from 1997 to 2004.

\section{Cases Ascertained}

Among the non-responders (group A, Fig. 2), six individuals had RA diagnoses in the DNHR and four had ever $R A$. No individuals from group A were examined. In the group of responders who did not self-report RA (group B, Fig. 2), four individuals made comments indicating RA but one did not want to attend for the examination. Five were registered in the DNHR. One individual, who was registered in the DNHR also made comments indicating RA.

Eighty-one individuals who self-reported RA (group C, Fig. 2) were not eligible for the clinical examination (67 did not want to attend, eight could not be reached by phone to arrange the examination or to carry out the telephone interview, six questionnaires had been handed over to and returned by individuals not in the sample) and 14 had ever $R A$. A subgroup of 30 individuals answered "yes" to all items and seven were ever $R A$ cases.

Out of the remaining 182 individuals who self-reported RA (group D, Fig. 2), 125 were interviewed by phone and eight were invited for the examination. Fifty-seven individuals were invited directly for the examination (48 answered "yes" to all five items, nine with positive diagnoses in the DNHR). A subgroup of 55 individuals answered "yes" to all items but when contacted to plan the examination, seven made comments that made RA less likely and they were not invited after the telephone interview.

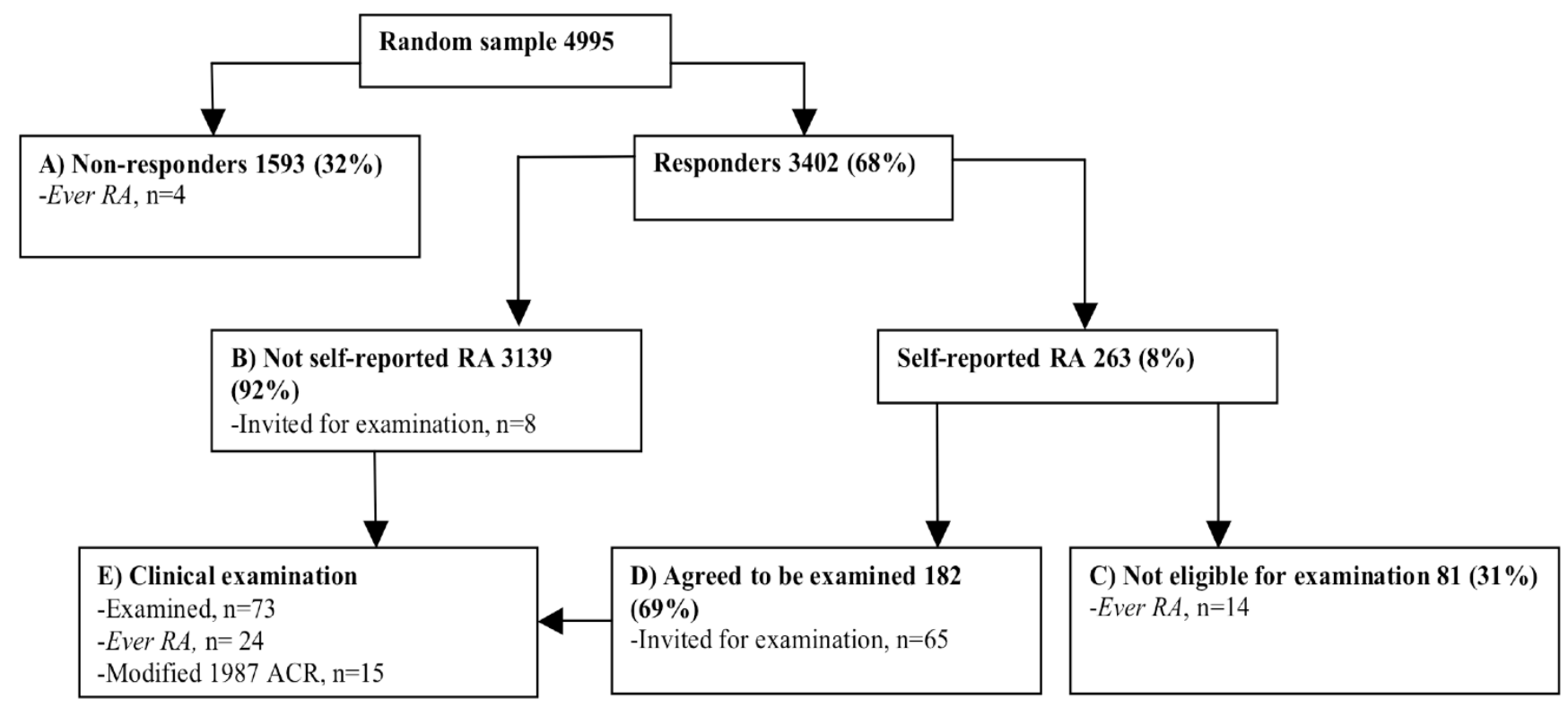

RA: rheumatoid arthritis. Self-reported RA: Individuals answering "yes" to the first item on screening mail questionnaire ("Have you or have you ever had rheumatoid arthritis"). Case definitions: Ever RA, fulfilment of the 1987 American College of Rheumatology (ACR) criteria documented in medical records or by questionnaire or fulfilment of the modified 1987 ACR criteria at examination; Modified 1987 ACR, fulfilment of the modified 1987 ACR criteria at examination.

Fig. (2). Response to screening questionnaire, selection for clinical examination, and numbers of cases ascertained in a sample of the population in the southern part of Denmark. 
Table 1. Response Rate, Crude and Adjusted* Point Prevalence and Cumulative Prevalence of Rheumatoid Arthritis According to Age and Sex in a Random Sample of the Population in the Southern Part of Denmark (95\% Confidence Interval)

\begin{tabular}{|c|c|c|c|c|c|c|c|c|c|}
\hline & \multicolumn{3}{|c|}{ Females } & \multicolumn{3}{|c|}{ Males } & \multicolumn{3}{|c|}{ Females and Males } \\
\hline & $15-59$ & $60+$ & All & 15-59 & $60+$ & All & $15-59$ & $60+$ & All \\
\hline Response rate, $\%$ & 70 & 76 & 72 & 58 & 77 & 64 & 64 & 77 & 68 \\
\hline \multicolumn{10}{|l|}{ Prevalence, responders } \\
\hline Responders, $\mathrm{n}$ & 1235 & 642 & 1877 & 993 & 532 & 1525 & 2228 & 1174 & 3402 \\
\hline Modified 1987 ACR, n & 3 & 7 & 10 & 0 & 5 & 5 & 3 & 12 & 15 \\
\hline Point prevalence, $\%$ & $\begin{array}{c}0.24 \\
(0.05-0.71)\end{array}$ & $\begin{array}{c}1.09 \\
(0.44-2.23)\end{array}$ & $\begin{array}{c}0.53 \\
(0.26-0.98)\end{array}$ & $\begin{array}{c}0 \\
(0.00-0.37)\end{array}$ & $\begin{array}{c}0.94 \\
(0.31-2.18)\end{array}$ & $\begin{array}{c}0.33 \\
(0.11-0.76)\end{array}$ & $\begin{array}{c}0.14 \\
(0.03-0.39)\end{array}$ & $\begin{array}{c}1.02 \\
(0.53-1.78)\end{array}$ & $\begin{array}{c}0.44 \\
(0.25-0.73)\end{array}$ \\
\hline $\begin{array}{l}\text { Adjusted point } \\
\text { prevalence, } \%\end{array}$ & & & $\begin{array}{c}0.46 \\
(0.17-0.74)\end{array}$ & & & $\begin{array}{c}0.24 \\
(0.03-0.44)\end{array}$ & & & $\begin{array}{c}0.35 \\
(0.17-0.52)\end{array}$ \\
\hline Ever $R A, \mathrm{n}$ & 10 & 17 & 27 & 1 & 10 & 11 & 11 & 27 & 38 \\
\hline $\begin{array}{l}\text { Cumulative } \\
\text { prevalence, } \%\end{array}$ & $\begin{array}{c}0.81 \\
(0.39-1.48)\end{array}$ & $\begin{array}{c}2.65 \\
(1.55-4.21)\end{array}$ & $\begin{array}{c}1.44 \\
(0.95-2.10)\end{array}$ & $\begin{array}{c}0.10 \\
(0.00-0.56)\end{array}$ & $\begin{array}{c}1.88 \\
(0.91-3.43)\end{array}$ & $\begin{array}{c}0.72 \\
(0.36-1.29)\end{array}$ & $\begin{array}{c}0.49 \\
(0.25-0.88)\end{array}$ & $\begin{array}{c}2.30 \\
(1.52-3.33)\end{array}$ & $\begin{array}{c}1.12 \\
(0.79-1.53)\end{array}$ \\
\hline $\begin{array}{l}\text { Adjusted cumulative } \\
\text { prevalence, } \%\end{array}$ & & & $\begin{array}{c}1.27 \\
(0.79-1.76)\end{array}$ & & & $\begin{array}{c}0.55 \\
(0.22-0.79)\end{array}$ & & & $\begin{array}{c}0.92 \\
(0.62-1.21)\end{array}$ \\
\hline \multicolumn{10}{|l|}{ Prevalence, total sample } \\
\hline Total sample, $\mathrm{n}$ & 1757 & 840 & 2597 & 1709 & 689 & 2398 & 3466 & 1529 & 4995 \\
\hline Modified 1987 ACR, n & 3 & 7 & 10 & 0 & 5 & 5 & 3 & 12 & 15 \\
\hline Point prevalence, $\%$ & $\begin{array}{c}0.17 \\
(0.04-0.50) \\
\end{array}$ & $\begin{array}{c}0.83 \\
(0.34-1.71) \\
\end{array}$ & $\begin{array}{c}0.39 \\
(0.19-0.71) \\
\end{array}$ & $\begin{array}{c}0 \\
(0.00-0.22) \\
\end{array}$ & $\begin{array}{c}0.73 \\
(0.24-1.69) \\
\end{array}$ & $\begin{array}{c}0.21 \\
(0.07-0.49) \\
\end{array}$ & $\begin{array}{c}0.09 \\
(0.02-0.25) \\
\end{array}$ & $\begin{array}{c}0.79 \\
(0.41-1.37) \\
\end{array}$ & $\begin{array}{c}0.30 \\
(0.17-0.50) \\
\end{array}$ \\
\hline $\begin{array}{c}\text { Adjusted point } \\
\text { prevalence, } \%\end{array}$ & & & $\begin{array}{c}0.34 \\
(0.13-0.55)\end{array}$ & & & $\begin{array}{c}0.18 \\
(0.02-0.34)\end{array}$ & & & $\begin{array}{c}0.26 \\
(0.13-0.39)\end{array}$ \\
\hline Ever $R A, \mathrm{n}$ & 10 & 21 & 31 & 1 & 10 & 11 & 11 & 31 & 42 \\
\hline $\begin{array}{l}\text { Cumulative } \\
\text { prevalence, } \%\end{array}$ & $\begin{array}{c}0.57 \\
(0.27-1.05)\end{array}$ & $\begin{array}{c}2.50 \\
(1.55-3.80)\end{array}$ & $\begin{array}{c}1.19 \\
(0.81-1.69)\end{array}$ & $\begin{array}{c}0.06 \\
(0.00-0.33)\end{array}$ & $\begin{array}{c}1.45 \\
(0.70-2.65)\end{array}$ & $\begin{array}{c}0.46 \\
(0.23-0.82)\end{array}$ & $\begin{array}{c}0.32 \\
(0.16-0.57)\end{array}$ & $\begin{array}{c}2.03 \\
(1.38-2.87)\end{array}$ & $\begin{array}{c}0.84 \\
(0.61-1.14)\end{array}$ \\
\hline $\begin{array}{l}\text { Adjusted cumulative } \\
\text { prevalence, } \%\end{array}$ & & & $\begin{array}{c}1.06 \\
(0.68-1.43)\end{array}$ & & & $\begin{array}{c}0.41 \\
(0.17-0.65)\end{array}$ & & & $\begin{array}{c}0.75 \\
(0.52-0.97)\end{array}$ \\
\hline
\end{tabular}

*Adjusted for age or age and sex to the 2004 Danish population using the direct method. Case definitions: Modified 1987 ACR, fulfilment of the modified 1987 American College of Rheumatology (ACR) criteria for rheumatoid arthritis at examination. Ever RA fulfilment of the 1987 ACR criteria documented in medical records or by questionnaire or fulfilment of the modified 1987 ACR criteria at examination.

A total of 73 individuals were examined and 24 had ever $R A$ (group E, Fig. 2), one individual came from group $\mathrm{B}$ and 23 from group D. Nineteen ever $R A$ cases $(79 \%)$ were currently treated with DMARDs. On the day of the examination, 15 individuals fulfilled the modified 1987 ACR criteria.

\section{Prevalence}

Among the responders a total of 38 ever $R A$ cases were identified and the cumulative prevalence $0.92 \%$ (Table 1 ). In the total sample 42 cases were identified and the cumulative prevalence was $0.75 \%$. Using the modified 1987 ACR criteria, the point prevalence was $0.35 \%$ among the responders and $0.26 \%$ in the total sample. The prevalence was highest among women and the elderly.

\section{DISCUSSION}

Using an extensive ascertainment procedure, we have provided updated estimates of the prevalence of RA in Denmark.
After one reminder the overall response rate to the screening mail questionnaire was $68 \%$. This is similar to other studies combining the results of a survey with register data where response rates have been $49 \%$ to $74 \%$ [15-18]. Using up to three reminders may lead to a higher response rate [3].

Some comments on the approach used for selecting individuals for the clinical examination are needed. In previous studies RA has only been ascertained in about one in five individuals who self-report RA in an interview or a questionnaire [19-22]. Instead of examining every individual who self-reported RA we used a telephone interview to exclude a subgroup of responders in whom we expected it to be impossible to ascertain the fulfilment of the classification criteria at a clinical examination. Recently, a standardized telephone interview conducted by laypeople has been described as a valid method to identify individuals with RA from a survey [23]. In our study, the decision on who was invited for the clinical examination was made by a physician and it was not based on a pre-defined, validated algorithm. 
When making the decision the physician probably used all available sources of information, including intuition and his prior theoretical and clinical experience. Using this approach we probably excluded individuals who did not know that in the nomenclature used by physicians RA refers to a specific disease and not rheumatic symptoms in general. This is supported by the fact that no individuals excluded from the examination using this approach were ascertained as ever $R A$ cases using register data.

The results of the pilot study evaluating the performance of the questionnaire suggested that using a specific test (i.e. all five items on the questionnaire) for screening, some false positive results were still to be expected. Accordingly, instead of being examined seven individuals who answered "yes" to all five items on the questionnaire were telephone interviewed because they made comments that made RA seem less likely. For instance, one individual indicated that the only symptom of RA was low back pain after an accident. None of these seven individuals were ascertained as ever $R A$ cases using register data.

The responders could write a short message on the screening questionnaire. Only a few messages were judged as being strong indicators of RA but one individual (from group B, Fig. 2) who used this option was ascertained as having ever RA. However, the same individual was also registered in the DNHR and in our study the sensitivity of the screening procedure was not improved by allowing an informal message to be included on the questionnaire.

In a sensitivity analysis of the estimates of the cumulative prevalence the most extreme scenario would be that all nonresponders to the screening questionnaire (group A, Fig. 2) were ever $R A$ cases. In our study, however, a more plausible estimate is generated by assuming that the fraction of individuals with RA among the non-responders was the same as among the responders. In this scenario there would have been a total of 18 ever $R A$ cases $(0.0112 * 1593 \approx 18)$ among the non-responders. We actually identified four ever $R A$ cases among the non-responders using the DNHR and this underlines that the DNHR may be a useful tool in epidemiological research [24]. Among the non-responders the mean age and the fraction of females were lower than among the responders. Since the prevalence of RA increases with age in most age groups and female preponderance is typical [3], it is less likely that we may have missed several cases among the non-responders.

From the medical records it appeared that one individual with ever $R A$ had been diagnosed as having juvenile idiopathic arthritis and one as having psoriatic arthritis. However, the classification criteria used in our study are without exclusion criteria and both were included as cases.

Using the original or modified 1987 ACR criteria the overall cumulative prevalence has been estimated in four studies combining the results of a survey with register data [15-18]. In Dublin, Ireland, the prevalence was $0.49 \%$ [15] and in Halland, Sweden, it was $0.51 \%$ [16]. In Oslo, Norway, the prevalence was $0.44 \%$ [17] and in Chiavari, Italy, it was $0.36 \%[18]$. By sampling telephone numbers and conducting telephone interviews the cumulative prevalence of RA in France was $0.31 \%$ [25] and in Lithuania it was $0.55 \%$ [26]. In Rochester, Minnesota, detailed medical data are collected systematically from health care facilities serving the community and in 2007 the cumulative prevalence of RA was $0.72 \%$ [27]. In our study we identified ever $R A$ cases among the responders and the non-responders and we therefore believe that the most reasonable estimate of the cumulative prevalence of RA was between $0.75 \%$ and $0.92 \%$.

The comparison of prevalence estimates from different populations and time periods may be hampered for various reasons. For instance, RA is an inflammatory disease with episodic activity and individuals with RA may have different symptoms and knowledge about the disease according to disease severity. This makes it inherently difficult to measure the prevalence of RA using a short screening questionnaire that may not cover the many factors associated with the varying phenotype of RA. However, the discrepancy in prevalence estimates between our study and other populations using the results of a survey combined with register data [15-18] may reflect differences in completeness of registrations [28], quality of coding, and the accuracy of clinical diagnoses [29].

Turning to the estimates of the point prevalence, a total of 18 individuals were ascertained as ever $R A$ cases using register data, but they did not return the questionnaire nor wanted to participate in the clinical examination (group A and C, Fig. 2). Most of them were outpatients at the rheumatology hospital and when invited they indicated that they did not have time for an additional examination at the hospital. If we assume that the 18 ever $R A$ case had all been responders and the same proportion as in group E (Fig. 2) would have satisfied the modified 1987 ACR criteria if examined, a total of 11 cases would have been missed $(15 / 24 * 18 \approx 11)$. Moreover, the modified 1987 criteria were not fulfilled in four ever $R A$ cases at the clinical examination, probably due to drug induced remission. Thus, in the present study the point prevalence was most likely underestimated because of low participation rate in the clinical examination and drug induced remission. Examining individuals in their homes may lead to a higher participation rate [3].

In other recent studies [3, 30-36], the overall point prevalence of RA has ranged from $0.38 \%$ [30] to $0.67 \%$ [36].

In the 1960s the point prevalence of RA (probable, classic, and definite RA) was $0.85 \%$ in a nationwide random sample of the Danish population. As case definition Sørensen used the Rome criteria for active and inactive RA [7]. When comparing the adjusted point prevalence from the present study with the results of the study by Sørensen, the occurrence of RA in Denmark may have decreased over the last four decades (Table 2). The highest decrease seems to have occurred in females, which is in line with other studies. A decrease in the point prevalence of RA has been observed in females from the UK between the 1950s and 1990 [2] and the 1950s and 2000 [3], perhaps caused by the introduction of the oral contraceptive pill [2,3]. A decrease has also been observed in female Pima Indians between 1965 and 1990 [5], and a decrease has been suggested in a Japanese population from 1965 to 1996 [4]. 
Table 2. Crude and Adjusted* Point Prevalence of Rheumatoid Arthritis in Two Danish Surveys, \%

\begin{tabular}{|c|c|c|c|c|c|}
\hline & \multicolumn{2}{|c|}{ Nationwide Sample, 1961-1962 ${ }^{\S}$} & \multicolumn{2}{|c|}{ Southern Part of Denmark, 2004 ${ }^{\#}$} & \multicolumn{2}{|c|}{ Adjusted } \\
\cline { 2 - 6 } & Crude & Adjusted & Crude & 0.46 & $-1.13(-71)$ \\
\hline \hline Females & 1.35 & 1.59 & 0.53 & 0.24 & $-0.16(-40)$ \\
\hline Males & 0.34 & 0.40 & 0.44 & 0.35 & $-0.69(-66)$ \\
\hline
\end{tabular}

*Adjusted for age or age and sex to the 2004 Danish population using the direct method. ${ }^{\S}$ Rome criteria for active and inactive rheumatoid arthritis [7]. ${ }^{\#}$ Modified 1987 American College of Rheumatology criteria for rheumatoid arthritis [14].

In the study by Sørensen individuals with probable RA according to the Rome criteria were included as cases [7], but they would probably not fulfil the modified 1987 ACR criteria used in the present study. Moreover, in our study the point prevalence was most likely underestimated. Taking these biases into account a true secular decline in the prevalence of RA in Denmark seems less convincing.

\section{CONCLUSION}

Using an extensive ascertainment procedure we have provided updated estimates of the prevalence of RA in Denmark. The point prevalence of RA was most likely underestimated due to low participation rate and druginduced remission among the individuals who attended the clinical examination. However, the cumulative prevalence was higher than reported in other studies combining the results of a survey with register data.

\section{ACKNOWLEDGEMENTS}

The study was funded by the County of South Jutland, Denmark; the Danish Rheumatism Association; the Margarethe Astrid Hedvig Schaufuss Grant; Grocer Hans Christensen's Memorial Grant.

\section{CONFLICT OF INTEREST}

None declared.

\section{REFERENCES}

[1] Silman AJ. In: Silman AJ, Hochberg MC, Eds. Epidemiology of the rheumatic diseases. 2nd ed. Oxford, Oxford University Press 2001; pp. 31-71.

[2] Spector TD, Hart DJ, Powell RJ. Prevalence of rheumatoid arthritis and rheumatoid factor in women: evidence for a secular decline. Ann Rheum Dis 1993; 52: 254-7.

[3] Symmons D, Turner G, Webb R, et al. The prevalence of rheumatoid arthritis in the United Kingdom: new estimates for a new century. Rheumatology (Oxford) 2002; 41: 793-800.

[4] Shichikawa K, Inoue K, Hirota S, et al. Changes in the incidence and prevalence of rheumatoid arthritis in Kamitonda, Wakayama, Japan, 1965-1996. Ann Rheum Dis 1999; 58: 751-6.

[5] Jacobsson LT, Hanson RL, Knowler WC, et al. Decreasing incidence and prevalence of rheumatoid arthritis in Pima Indians over a twenty-five-year period. Arthritis Rheum 1994; 37: 1158-65.

[6] Helmick CG, Felson DT, Lawrence RC, et al. Estimates of the prevalence of arthritis and other rheumatic conditions in the United States. Part I. Arthritis Rheum 2008; 58: 15-25.

[7] Sørensen K. Rheumatoid arthritis in Denmark. Two population studies. Dan Med Bull 1973; 20: 86-93.

[8] Recht L, Helin P, Rasmussen JO, Jacobsen J, Lithman T, Scherstén B. Hand handicap and rheumatoid arthritis in a fish-eating society (the Faroe Islands). J Intern Med 1990; 227: 49-55.

[9] Pattison DJ, Harrison RA, Symmons DP. The role of diet in susceptibility to rheumatoid arthritis: a systematic review. J Rheumatol 2004; 31: 1310-9.
[10] MacGregor AJ, Silman AJ. A reappraisal of the measurement of disease occurrence in rheumatoid arthritis. J Rheumatol 1992; 19: 1163-5.

[11] Altman DG. Practical statistics for medical research. 1st ed. London: Chapman-Hill 1991.

[12] Arnett FC, Edworthy SM, Bloch DA, et al. The American Rheumatism Association 1987 revised criteria for the classification of rheumatoid arthritis. Arthritis Rheum 1988; 31: 315-24.

[13] Andersen TF, Madsen M, Jørgensen J, Mellemkjoer L, Olsen JH. The Danish National Hospital Register. A valuable source of data for modern health sciences. Dan Med Bull 1999; 46: 263-8.

[14] MacGregor AJ, Bamber S, Silman AJ. A comparison of the performance of different methods of disease classification for rheumatoid arthritis. Results of an analysis from a nationwide twin study. J Rheumatol 1994; 21: 1420-6.

[15] Power D, Codd M, Ivers L, Sant S, Barry M. Prevalence of rheumatoid arthritis in Dublin, Ireland: a population based survey. Ir J Med Sci 1999; 168: 197-200.

[16] Simonsson M, Bergman S, Jacobsson LT, Petterson IF, Svensson B. The prevalence of rheumatoid arthritis in Sweden. Scand J Rheumatol 1999; 28: 340-3.

[17] Kvien TK, Glennas A, Knudsrød OG, Smedstad LM, Mowinckel P, Førre O. The prevalence and severity of rheumatoid arthritis in Oslo. Results from a county register and a population survey. Scand J Rheumatol 1997; 26: 412-8.

[18] Cimmino MA, Parisi M, Moggiana G, Mela GS, Accardo S Prevalence of rheumatoid arthritis in Italy: the Chiavari Study. Ann Rheum Dis 1998; 57: 315-8.

[19] Ling SM, Fried LP, Garrett E, Hirsch R, Guralnik JM, Hochberg MC. The accuracy of self-report of physician diagnosed rheumatoid arthritis in moderately to severely disabled older women. Women's Health and Aging Collaborative Research Group. J Rheumatol 2000; 27: 1390-4.

[20] Gram IT, Riise T, Honda Y. Rheumatoid arthritis: a commonly misused diagnosis by the general population. Clin Rheumatol 1997; 16: 264-6.

[21] Star VL, Scott JC, Sherwin R, Lane N, Nevitt MC, Hochberg MC Validity of self-reported rheumatoid arthritis in elderly women. J Rheumatol 1996; 23: 1862-5.

[22] Kvien TK, Glennås A, Knudsrød OG, Smedstad LM. The validity of self-reported diagnosis of rhematoid arthritis: results from a population survey followed by clinical examinations. J Rheumatol 1996; 23: 1866-71.

[23] Guillemin F, Saraux A, Fardellone P, Guggenbuhl P, Behier JM, Coste J. Detection of cases of inflammatory rheumatic disorders: performance of a telephone questionnaire designed for use by patient interviewers. Ann Rheum Dis 2003; 62: 957-63.

[24] Pedersen M, Klarlund M, Jacobsen S, Svendsen AJ, Frisch M. Validity of rheumatoid arthritis diagnoses in the Danish National Patient Registry. Eur J Epidemiol 2004; 19: 1097-103.

[25] Guillemin F, Saraux A, Guggenbuhl P, et al. Prevalence of rheumatoid arthritis in France: 2001. Ann Rheum Dis 2005; 64: 1427-30.

[26] Adomaviciute D, Pileckyte M, Baranauskaite A, Morvan J, Dadoniene J, Guillemin F. Prevalence survey of rheumatoid arthritis and spondyloarthropathy in Lithuania. Scand J Rheumatol 2008; 37: 113-9.

[27] Myasoedova E, Crowson CS, Kremers HM, Therneau TM, Gabriel SE. Is the incidence of rheumatoid arthritis rising?: Results from Olmsted County, Minnesota, 1955-2007. Arthritis Rheum 2010; 62: 1576-82. 
[28] Goldberg J, Gelfand HM, Levy PS. Registry evaluation methods: a review and case study. Epidemiol Rev 1980; 2: 210-20.

[29] Sorensen HT, Sabroe S, Olsen J. A framework for evaluation of secondary data sources for epidemiological research. Int J Epidemiol 1996; 25: 435-42.

[30] Kacar C, Gilgil E, Tuncer T, et al. Prevalence of rheumatoid arthritis in Antalya, Turkey. Clin Rheumatol 2005; 24: 212-21.

[31] Akar S, Birlik M, Gurler O, et al. The prevalence of rheumatoid arthritis in an urban population of Izmir- Turkey. Clin Exp Rheumatol 2004; 22: 416-20.

[32] Salaffi F, De Angelis R, Grassi W; MArche Pain Prevalence; Investigation Group (MAPPING) study. Prevalence of musculoskeletal conditions in an Italian population sample: results of a regional community-based study. I. The MAPPING study. Clin Exp Rheumatol 2005; 23: 819-28.
[33] Carmona L, Villaverde V, Hernandez-Garcia C, et al. The prevalence of rheumatoid arthritis in the general population of Spain. Rheumatology (Oxford) 2002; 41: 88-95.

[34] Kiss CG, Lovei C, Suto G, et al. Prevalence of rheumatoid arthritis in the South-Transdanubian region of Hungary based on a representative survey of 10,000 inhabitants. J Rheumatol 2005; 32: 1688-90.

[35] Hanova P, Pavelka K, Dostal C, Holcatova I, Pikhart H. Epidemiology of rheumatoid arthritis, juvenile idiopathic arthritis and gout in two regions of the Czech Republic in a descriptive population-based survey in 2002-2003. Clin Exp Rheumatol 2006; 24: 499-507.

[36] Andrianakos A, Trontzas P, Christoyannis F, et al. Prevalence of rheumatic diseases in Greece: a cross-sectional population based epidemiological study. The ESORDIG study. J Rheumatol 2003; 30: $1589-1601$

Received: May 15, 2011

Revised: May 19, 2011

Accepted: May 21, 2011

(C) Pedersen et al.; Licensee Bentham Open.

This is an open access article licensed under the terms of the Creative Commons Attribution Non-Commercial License (http://creativecommons.org/licenses/by-nc/ 3.0/) which permits unrestricted, non-commercial use, distribution and reproduction in any medium, provided the work is properly cited. 